\title{
PRODUCTION OF BIO-ETHANOL FROM JATROPHA OILSEED CAKES VIA DILUTE ACID HYDROLYSIS AND FERMENTATION BY SACCHAROMYCES CEREVISIAE
}

\author{
MOHIT S. MISHRA ${ }^{*}$, CHANDRASHEKHAR B., TANUSHREE CHATTERJEE AND KANWAL SINGH ${ }^{1}$ \\ "Department of Biotechnology, Raipur Institute of Technology, Raipur, India \\ ${ }^{1}$ Research and Development cell MATS University, Raipur , India \\ *Corresponding Author: Email- mishra.msbiotech@gmail.com
}

Received: October 28, 2010; Accepted: March 09, 2011

\begin{abstract}
This work deals with the bioconversion of cellulose from press cakes of Jatropha oilseeds, which is a byproduct from a biodiesel plant, into ethanol by using the methods of acid pretreatment, hydrolysis and fermentation by Saccharomyces cerevisiae. The process includes the pretreatment method of the finely ground cellulosic solid oilseed cake with dilute sulphuric acid and heating the mixture at a high temperature to break the crystalline structure of the lignocellulose to facilitate the hydrolysis of cellulosic component by dilute acids. The hydrolysis of the cellulose content into sugars is done by dilute acid hydrolysis that involves incubation period at a high temperature for 72 hours. Finally, the fermentation of the hydrolyzed waste is done using Saccharomyces cerevisiae under proper incubation conditions to produce ethanol. About $80 \%$ ethanol was recovered as a result of the process.
\end{abstract}

Key words - Jatropha oilseed press cake, lignocellulose, pretreatment, acid hydrolysis, bio-ethanol

\section{Introduction}

Ethanol is a renewable substitute of petroleum fuels such as petrol and gasoline. Presently, major portion of the ethanol produced worldwide is produced by the fermentation of sugars obtained from molasses, cereals, and fruits. Cellulose is an abundantly found carbohydrate and is found in many wastes such a sludge, paper and pulp, wood, textile waste etc. Utilization of cellulose for the production of ethanol may minimize the current dependence of the world on petroleum fuels and. The process of obtaining ethanol from various cellulosic wastes has been worked out in the past [1,2]. All such processes involve the three important steps- mechanical processing and pretreatment of the material; hydrolysis of the pretreated material; and finally fermentation of the hydrolyzed material by a suitable microorganism to produce ethanol.

Pretreatment breaks the crystalline structure of the lignocellulose and removes the lignin to expose the cellulose and hemi cellulose molecules to facilitate the cellulose hydrolysis by either acids or enzymes. This is important because hydrolysis, which is the next step, can be affected by porosity of lignocellulosic biomass, cellulose fiber crystallinity, and lignin and hemicellulose content. Depending on the biomass material, either physical or chemical pretreatment methods may be used. Methods used for cellulosic materials require much more intense physical pretreatments such as 'steam explosion'. Pilanee Vaithanomsat et al [3] have utilized steam explosion method for the pretreatment of the sunflower stalks for bioethanol production. Addition of catalyst such as sulfuric acid has been found to improve the pretreatment $[4,17]$. However, the steam explosion method is expensive and requires more capital, so chemical methods of pretreatment have been developed as alternative. Chemical pretreatment of cellulosic materials is done by using chemicals such as dilute acid, alkali, organic solvent, ammonia, sulfur dioxide, carbon dioxide or other chemicals to make the biomass more digestible by the enzymes. Keikhosro Karimi et al [5] have used chemical pretreatment method by using dilute $\mathrm{H}_{2} \mathrm{SO}_{4}$ for ethanol production from rice straw. The pretreatment can be done by using sodium hydroxide after it is finely ground $[6,18]$. Pretreatment of cellulosic biomass in a cost-effective manner is a major challenge of cellulose-ethanol technology research and development. The pretreatment is followed by hydrolysis of the raw materials. Plant cell walls are the source of lignocellulosic biomass, whose structure is chiefly represented by the physico-chemical interaction of cellulose, hemicellulose and lignin. Cellulose, the most abundant polysaccharide on earth, is a highly ordered polymer of cellobiose representing over $50 \%$ of the wood mass (Elba P.S. Bon et al) [7]. Hydrolysis is the process of breakdown of cellulose into cellobiose and glucose, which can be accomplished either by enzymes or by acid [8]. The enzymatic hydrolysis is accomplished by mixing the pretreated material with enzymes such as cellulase and 
beta-glucanase produced by microorganisms. Fatma $\mathrm{H}$. et al[6] have utilized Trichoderma Reesei for enzymatic hydrolysis. Such method of hydrolysis is called 'Direct Microbial Conversion' (DMC) which is a method of converting cellulosic biomass to ethanol in which both ethanol and all required enzymes are produced by a single microorganism. However, DMC is not considered the leading process alternatives today because there are no organisms available that both produce cellulase and other enzymes at the required high levels and also produce ethanol at the required high concentrations and yields. Another approach which uses enzyme hydrolysis is the Simultaneous Saccharification and Fermentation (SSF) which combined the cellulase enzymes and fermenting microbes in one vessel. This enabled a one-step process of sugar production and fermentation into ethanol. The disadvantage, however, is that the cellulase enzyme and fermentation organism have to operate under the same conditions, decreasing the sugar and ethanol yields.

The acid hydrolysis of the cellulosic substrate is an excellent alternative to the enzymatic hydrolysis. Two acid hydrolysis processes are commonly used: Hydrolysis by dilute acid and hydrolysis by concentrated acid. Most common acid used is sulfuric acid. The 'concentrated acid hydrolysis' method uses concentrated (40\%-70\%) sulfuric acid followed by a dilution with water to dissolve and hydrolyze or convert the substrate into sugar. The primary advantage of the concentrated process is the potential for high sugar recovery efficiency, about 90 percent of both hemicellulose and cellulose sugars. The major disadvantage of concentrated acid hydrolysis is that it requires the separation of sugars and acid from the mixture, which is necessary to increase the $\mathrm{pH}$ of the hydrolyzed substrate and also to recycle the acid from the mixture. It may be required to reduce the acidity of the mixture by adding alkali such as lime. The separation process requires techniques such as ion-exchange and multiple effect evaporators, which increase the cost of process. Dilute acid process is conducted under high temperature and pressure, and has a reaction time in the range of seconds or minutes, which facilitates continuous processing. The dilute acid process involves a solution of about 1-2 percent sulfuric acid concentration at a high temperature. Nutawan Yoswathana et al [9] have utilized dilute sulfuric acid (1-9\%) for the hydrolysis of rice straw for ethanol production. The major advantage of dilute acid hydrolysis is that it is quicker than concentrated acid hydrolysis and hence can be used as a continuous process. The disadvantage of this method is that the sugar conversion efficiency is only about $50 \%$. Also due to high temperature and pressure, large portion of the sugars is degraded which is not fermentable.

The hydrolyzed material is finally fermented with the help of suitable microorganism to produce ethanol. Different strategies have been employed for the fermentation depending on the raw material and the microorganism. A common method is Simultaneous Saccharification and Fermentation which is already mentioned before. Sequential hydrolysis and fermentation is also employed which the hydrolyzed material is transferred into a fermentor where fermentation under the desired conditions is carried out. H. D. Zakpaa et al $[10,16]$ have utilized the SSF method for the production of bio-ethanol from corncobs. Also different types of microorganisms have been used. Many genetically engineered microorganisms are developed that can utilize all five of the major biomass sugars - glucose, xylose, mannose, galactose and arabinose. Saccharomyces cerevisae, Zymomonas mobilis, Aspergillus niger are some of the widely used microorganisms for ethanol fermentation.

Jatropha is a tropical plant and the oil obtained from its seeds is widely used for the production of biodiesel. The press cake is produced as a byproduct of biodiesel production. The extraction of oil from jatropha oilseeds and its conversion into biodiesel involves many complex processes in which the cakes obtained from the press are the major byproducts [11]. The cake is dark brown to black in color and contains carbohydrates, fibers and rest of oil and is useful as organic fertilizer because the high content of nitrogen. The cake is also found to contain large amounts of water and carbon content along with low contents of hydrogen and oxygen [12].

Production of ethanol from jatropha oilseed press cakes by the conversion of cellulose into reducing sugars and fermenting the sugars into ethanol is useful for the Jatropha biodiesel industry since two important biofuels can be produced from the price of one raw material i.e., Jatropha oilseeds, by setting up an integrated unit for the production of ethanol by fermentation in the biodiesel production plant. Since, the method for utilization of the oilseed cake for ethanol production has not been developed; as such the following work is novel.

\section{Materials and Methods}

The overall process involves the following stepsPretreatment of the oilseed cakes, Hydrolysis of the pretreated material to release reducing sugars and Fermentation of the released sugars, to produce ethanol.

\subsection{Collection and preparation of jatropha oilseed press cake}

Jatropha oilseed press cake was collected from Biodiesel plant, Energy Park, Raipur. The cakes were initially crushed to 0.5-0.6 inches and soaked in water for overnight to remove dirt and excess oil. The oil slowly left the cake to float on the water surface. The cakes were then separated from the dirty water using a sieve and dried in air to make the weight constant before pretreatment.

\subsection{Collection of microorganisms:}

Saccharomyces cerevisiae was isolated from rotten grapes using techniques such as serial dilution and spread plate 
method using Potato-Dextrose Agar Medium and identified by observing the cells under a compound microscope. Pure culture of the yeast was prepared on Saubourd's Agar Media by keeping the plate at $37 \mathrm{C}$ for at least 4 days and was maintained on YPD (yeast extract/peptone/dextrose) agar slants sealed with sterile mineral oil at room temperature $\left(25^{\circ} \mathrm{C}\right)$. The strain was subcultured to YPD agar slants and incubated at $25^{\circ} \mathrm{C}$ for 3 days and then used to inoculate preculture broths. The preculture broth was prepared by inoculating sucrose broth with a loop full of the cultured yeast and when the density of the yeast cells in the liquid medium was adequate, i.e. a $24 \mathrm{~h}$ suspension of $S$. cerevisiae at $\mathrm{OD}_{660}=0.6$, was used as the inoculum in the fermentation medium.

\subsection{Pretreatment:}

The size of the oil cakes was mechanically reduced using a grinder and a fine powder of 40 mesh size was obtained. The powder was dried at $45^{\circ} \mathrm{C}$ for 2 hours in a hot air oven to completely remove the moisture. Equal volume of $0.5 \%$ sulfuric acid was added since a higher yield is obtained with a catalyst like $\mathrm{H}_{2} \mathrm{SO}_{4}$. The mixture was heated under pressure at a temperature of $125-130 \mathrm{C}$ and $25 \mathrm{psi}$ pressure for 1 hour. The mixture was again dried with hot air at 30-35 C. Samples were collected from the pretreated material for analysis.

\subsection{Hydrolysis:}

The raw material (substrate) was hydrolyzed by dilute acid hydrolysis method by adding to the pretreated material twice the volume of $2 \%, 3 \%$ and $5 \% \mathrm{H}_{2} \mathrm{SO}_{4}$ and mixing well. The mixture was poured in glass bottles and sealed to prevent vaporization of acid due to heat. The mixture was kept at a high temperature of $55 \mathrm{C}$ for duration of 3 days. Regular mixing of the mixture was done to prevent precipitation. Samples were collected from the hydrolyzed material for analysis.

\subsection{Fermentation:}

Anaerobic batch fermentation of $200 \mathrm{ml}$ broth media consisting of pretreated and hydrolyzed jatropha oilseed cakes was carried out in order to convert the released sugars into ethanol, the conversion process being accomplished by the enzymes released by Saccharomyces cerevisiae. The $\mathrm{pH}$ of the solution was brought to 4.2 by adding required amount of $4 \mathrm{M} \mathrm{NaOH}$ to accommodate yeast growth. The volume of the broth was brought to 200 $\mathrm{ml}$ by adding required amount of distilled water. The hydrolyzed material was completely sterilized by autoclaving $\left(120^{\circ} \mathrm{C}, 15 \mathrm{psi}\right.$ pressure and $\left.30 \mathrm{~min}\right)$ before inoculating the yeast. Detoxification of the hydrolyzed material is not necessary as most of the toxins are detoxified due to the pretreatment and hydrolysis process (heat and chemicals). The mixture can be directly utilized as a broth for fermentation without additional detoxification methods. The fermentation was carried out in a closed conical flask at temperature of $32 \mathrm{C}$, agitation rate at 110$\mathrm{rpm}$ in shaker incubator. The mouths of the flasks were tightly sealed to maintain anaerobic condition and an outlet was provided to release $\mathrm{CO}_{2}$. The other end of the outlet was dipped in lime water to confirm the release of $\mathrm{CO}_{2}$ as it turns lime water milky. Triplicate fermentation broths of same composition were prepared and incubated in the same conditions. The fermentation was continued for 9 days and samples were taken from each of the three broths on each alternate day for analysis to get triplicate results.

\subsection{Distillation}

Simple Distillation of the broth after fermentation was done to recover ethanol from it. Triplicate samples of the distillate were analyzed to estimate the amount of ethanol.

\subsection{Analytical methods and calculations:}

Samples were regularly collected from each stage of the entire process. Benedict's test was done on the unhydrolyzed as well as the hydrolyzed oilseed cakes to test the presence of reducing sugars. Cellulose estimation was done by Anthrone method as explained by Sadasivam and Manickam in Biochemical Methods[13]. In this method $3 \mathrm{ml}$ acetic/nitric reagent was added to a known amount $(0.5 \mathrm{gm}$ or $1 \mathrm{gm})$ of the sample in a test tube and mixed well in a vortex meter. The tube was placed in a water bath at $100^{\circ} \mathrm{C}$ for $30 \mathrm{~min}$. The contents were cooled and then centrifuged for 15- $20 \mathrm{~min}$. The supernatant was discarded and the residue was washed with distilled water. $10 \mathrm{ml}$ of sulphuric acid was added and allowed to stand for $1 \mathrm{hr}$. One $\mathrm{ml}$ of the above solution was diluted to $100 \mathrm{ml}$. To $1 \mathrm{ml}$ of this diluted solution, $10 \mathrm{ml}$ of Anthrone reagent was added and mixed well. The tube was heated in boiling water bath for $10 \mathrm{~min}$. The tube was cooled and the color was measured at $630 \mathrm{~nm}$ using a spectrophotometer. The blank was set with Anthrone reagent and distilled water. The standards were prepared by taking $100 \mathrm{mg}$ cellulose in a test tube and following the same process as with the sample. Instead of just taking $1 \mathrm{ml}$ of the diluted solution, a series of volumes (say 0.4 to $2 \mathrm{ml}$ corresponding to $40-200$ $\mu \mathrm{g}$ of the cellulose) was taken and developed the color. The sugar estimation was done by was done by Dinitrosalisylic acid (DNS) method (Sadasivam and Manickam) [13] in which $0.5 \mathrm{ml}$ of the hydrolyzed and unhydrolyzed waste samples was added to a test tube and volume was made up to $1 \mathrm{ml}$ using distilled water. The test tubes were incubated at room temperature for 5 minutes, DNS reagent was added, mixed well and the test tubes were kept in water bath at $70^{\circ} \mathrm{C}$ for 10 minutes. The test tubes were cooled in cold water and $40 \% \mathrm{Na}$ - $\mathrm{K}$ tartarate was added to maintain the colour. Blank was prepared as above using $1 \mathrm{ml}$ of water in place of sample. Standard solutions were prepared by taking $1 \mathrm{ml}$ of a series of solutions with increasing concentration of glucose (i.e. 0.2 , $0.4,0.6,0.8$ and $1 \mathrm{gm}$ per $\mathrm{ml}$ ). The bright red color 
produced in each samples was measured at $540 \mathrm{~nm}$ against the blank. The results were compared with the standard graph and thus the concentration of glucose in the samples was estimated. In this way, both sugar and cellulose estimation was done in the oilseed cakes before and after pretreatment-hydrolysis stage.

Rate of hydrolysis and Cellulose Convertion (C.C) as a result of hydrolysis were calculated using the estimated data. The following formulae by Arthe R. et al [14] were used for calculating these two parameters:

Rate of hydrolysis:

$$
V=\frac{d S}{d t}=\frac{\text { Glucose }_{t}-\text { Glucose }_{t_{0}}}{t-t_{0}}
$$

Where, Glucose $t$ is the concentration of glucose after time $t$, and Glucose $_{0}$ is the concentration of glucose before hydrolysis. $t$ and $t_{0}$ are the final and the initial time in hours respectively.

The cellulose conversion (C.C) percentage:

$$
C . C=\frac{\left(\text { Glucose }_{t}-\text { Glucose }_{t_{0}}\right) 100}{C}
$$

Where, Glucoset is the concentration of glucose after time $t$, and Glucose 0 is the concentration of glucose before hydrolysis. $C$ is the concentration of cellulose before hydrolysis. The estimation of biomass, ethanol and reducing sugar (Glucose) in the broth was done on every alternate day of fermentation. The ethanol estimation was done by a modified form of potassium dichromate method as described by Caputi et al [15] while glucose estimation was done by DNS method. A UV-Visible spectrophotometer was used to measure the absorbance. Standard graphs were drawn for sugar and ethanol estimation and are shown in fig. All the samples were taken as triplicates for analysis and their average values were taken for calculations and plotting of graphs.

\section{Results and Discussion:}

The concentration of cellulose in Jatropha oilseed press cake after pretreatment step was estimated to be 26.66 $\mathrm{mg} / \mathrm{g}$ of sample. The amount of glucose in the unhydrolyzed oilseed cake was estimated to be $0.52 \mathrm{mg} / \mathrm{g}$ of sample. After hydrolysis with $2 \%$ sulfuric acid, the amount of glucose in the material increased to $17.68 \mathrm{mg} / \mathrm{g}$ of sample, after $3 \%$ sulfuric acid, the amount of glucose in the material increased to $17.90 \mathrm{mg} / \mathrm{g}$ of sample, and after hydrolysis with $5 \%$ sulfuric acid the amount of glucose increased to $18.60 \mathrm{mg} / \mathrm{g}$ of sample (Figure-1). The rate of hydrolysis (Figure-2) is calculated as -

With $5 \% \mathrm{H}_{2} \mathrm{SO}_{4}$,

$$
V=\frac{18.60-0.52 \mathrm{mg} / \mathrm{g}}{72-0 \mathrm{hr}}=0.250 \mathrm{mg} \mathrm{g}^{-1} \mathrm{hr}^{-1}
$$

With $3 \% \mathrm{H}_{2} \mathrm{SO}_{4}$,

$$
V=\frac{17.90-0.52 \mathrm{mg} / \mathrm{g}}{72-0 \mathrm{hr}}=0.241 \mathrm{mg} \mathrm{g}^{-1} \mathrm{hr}^{-1}
$$

With $2 \% \mathrm{H}_{2} \mathrm{SO}_{4}$,

$$
V=\frac{17.68-0.52 \mathrm{mg} / \mathrm{g}}{72-0 \mathrm{hr}}=0.238 \mathrm{mg} \mathrm{g}^{-1} \mathrm{hr}^{-1}
$$

Cellulose conversion percentage,

$$
\begin{aligned}
\text { With } 2 \% \mathrm{H}_{2} \mathrm{SO}_{4}, \mathrm{C} . \mathrm{C} \%= & \frac{(17.68-0.52)}{26.66 \mathrm{mg} / \mathrm{ml} \times 100} \mathrm{mg} / \mathrm{ml} \\
= & 0.643 \times 100 \\
= & \mathbf{6 4 . 3} \% \\
\text { With } 3 \% \mathrm{H}_{2} \mathrm{SO}_{4}, \text { C.C } \%= & \frac{(17.90-0.52)}{26.66} \mathrm{mg} / \mathrm{ml} \times 100 \\
= & 0.652 \times 100 \\
= & \mathbf{6 5 . 2} \%
\end{aligned}
$$

With $5 \% \mathrm{H}_{2} \mathrm{SO}_{4}$, C.C $\%=(18.60-0.52) \mathrm{mg} / \mathrm{ml} \times 100$ $26.66 \mathrm{mg} / \mathrm{ml}$ $=0.68 \times 100$ $=67.8 \%$

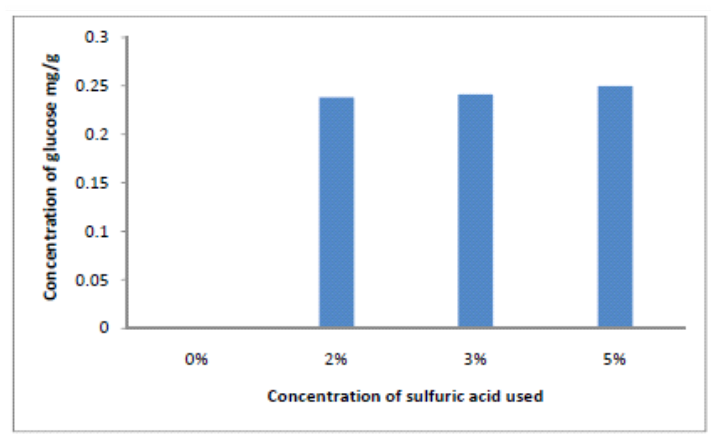

Fig. 1- Shows the amount of glucose released as a result of hydrolysis with $2 \%, 3 \%$ and $5 \% \mathrm{H}_{2} \mathrm{SO}_{4}$

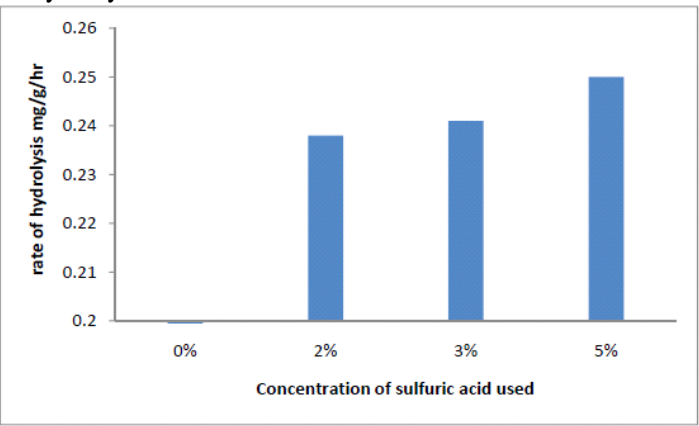

Fig. 2- Comparison of the rates of hydrolysis with $2 \%$ and $5 \% \mathrm{H}_{2} \mathrm{SO}_{4}$

Clearly rate of hydrolysis is more when hydrolysis is done with $5 \% \mathrm{H}_{2} \mathrm{SO}_{4}$. The estimation of glucose and ethanol concentration in the broth was done by drawing standard graphs (Fig. 3 and 4). The broth contained $9.75 \mathrm{mg} / \mathrm{ml}$ of 
glucose in the first day. Glucose was estimated in the broth on alternate days. After 9 days of fermentation the amount of glucose remained was $5.85 \mathrm{mg} / \mathrm{ml}$ as shown in Table 1 . The day wise consumption of glucose in the fermentation broth is shown in Fig. 5. Similarly, the estimation of ethanol in the broth after 1 day showed a concentration of 0.016 $\mathrm{ml} / \mathrm{ml}$ which gradually increased to $0.079 \mathrm{ml} / \mathrm{ml}$ in 9 days, as shown in Table 2 and Fig. 6 . Distillation of the broth was done by simple distillation method and at the end of the process about $14.60 \mathrm{ml}$ of ethanol was recovered from 250 $\mathrm{ml}$ fermentation broth.

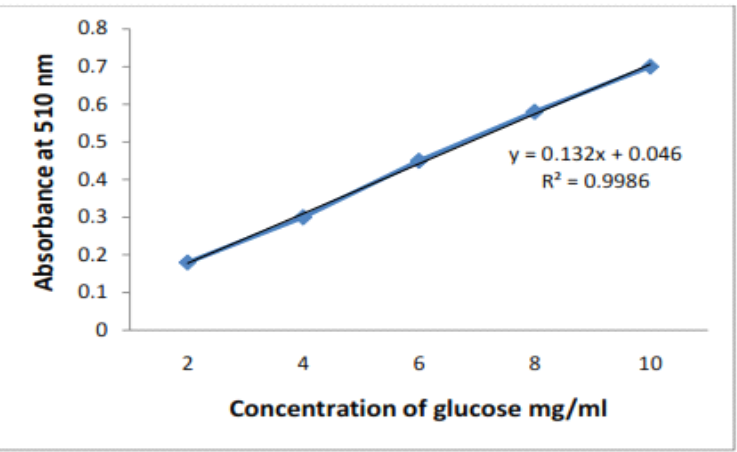

Fig. 3- Standard graph for Glucose Estimation

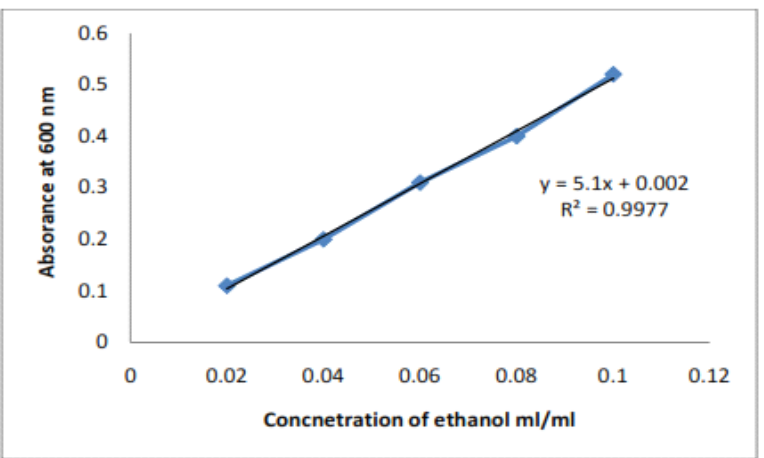

Fig. 4-Standard graph for Ethanol Estimation

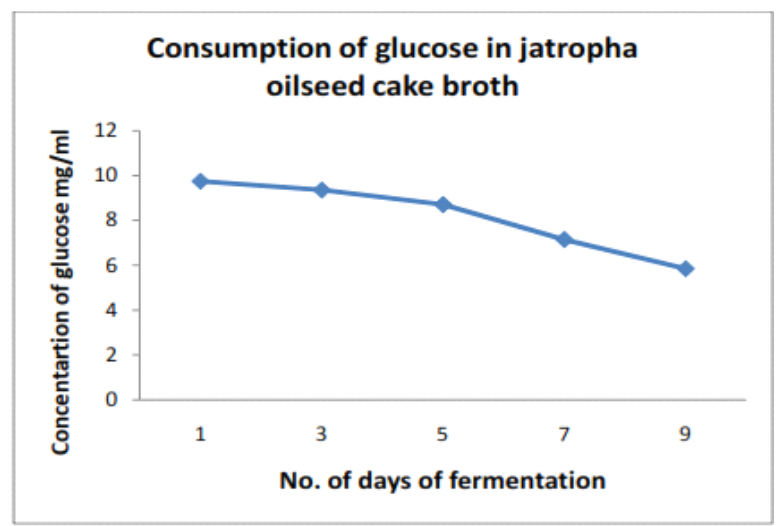

Fig. 5-Day wise estimation of glucose in the fermentation broth

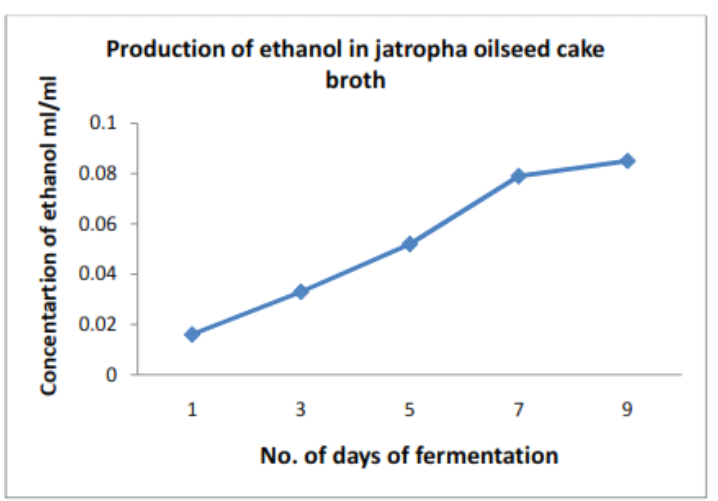

Fig. 7 Day wise estimation of ethanol in the fermentation broth

Jatropha oilseed cake has been found to be a good raw material for cellulosic ethanol production. The pretreatment and acid hydrolysis of oilseed cake to convert the cellulose into reducing sugars has shown positive results. The test for glucose in hydrolyzed and unhydrolyzed sample was carried out and the results suggest a positive outcome for cellulose hydrolysis throughout the process.

It is also confirmed that, the amount of released sugars upon hydrolysis increase with the concentration of acids used in the acid hydrolysis. The rate of hydrolysis of cellulose in the oilseed cake was found to be 0.250 and $0.238 \mathrm{mg} / \mathrm{ml}$ per hr when hydrolyzed with $5 \%$ and $2 \%$ $\mathrm{H}_{2} \mathrm{SO}_{4}$. So, by using $5 \% \mathrm{H}_{2} \mathrm{SO}_{4}$ we can achieve better rate of hydrolysis as well as cellulose conversion without seriously affecting the $\mathrm{pH}$ of the broth. Hydrolysis with $5 \%$ $\mathrm{H}_{2} \mathrm{SO}_{4}$ shows $68 \%$ conversion of cellulose and the estimation of glucose in the unhydrolyzed samples shows that the oilseed cake already has some amount of glucose in it. So, Jatropha oilseed cake produces enough amount of reducing sugars upon acid hydrolysis by dilute acids. The released sugars were fermented for 9 days and the estimation of ethanol after each alternate day in the respective broths of oilseed cake and cotton waste shows that the amount of ethanol increase each day, along with a regular decrease in the sugar content of the broth showing that large part of glucose was utilized by Saccharomyces cerevisiae and converted to ethanol. It was estimated that at the end of $9^{\text {th }}$ day of fermentation, atleast $8 \%$ ethanol was produced in the oilseed cake fermentation broth approximately.

The concentration of glucose broth was estimated to be around $9.75 \mathrm{mg} / \mathrm{ml}$ in the hydrolyzed Jatropha oilseed press cake which was reduced to $5.85 \mathrm{mg} / \mathrm{ml}$ at the end of fermentation. The rate of consumption of glucose is lesser in the first 4 days of fermentation, but increased during the next 5 days. Although the production of ethanol is slow, this clearly indicates that sugars released due to hydrolysis can be easily fermented by $S$. cerevisiae into ethanol. About $14.6 \mathrm{ml}$ ethanol was successfully recovered from the broth by simple distillation method which shows that the broth can be easily distilled to recover and purify ethanol. 


\section{Conclusion}

It can be concluded that jatropha oilseed press cake has a capability to undergo acid hydrolysis and fermentation for production of bio-ethanol. Jatropha oilseed cake is a good source of cellulose and can be utilized for cellulosic ethanol production. In the future the Jatropha oilseed cake, which is a waste byproduct of the biodiesel plant can be used as a good raw material for ethanol production and also solve the problem of safe disposal of the byproduct. In the future further improvements in the process can be carried out to enhance the productivity. It can also encourage Jatropha plantation and the development the biodiesel industry, as two important biofuels, biodiesel and bioethanol can be produced from the price of only one raw material.

\section{Acknowledgement}

We sincerely thank Dr. Tanushree Chatterjee, HOD, Department of Biotechnology, Raipur Institute of Technology, Raipur, for giving us kind permission and all kinds of support to undertake this project. We are thankful to our labmates, colleages and friends for their needed support.

\section{Acknowledgement}

Financial contributions to the work being reported should be clearly acknowledged, as should any potential conflict of interest.

\section{References}

[1] Clifford Louime, Hannah Uckelmann (2008) Inernational Journal of Molecular Science, 9, 838-841.

[2] Jin-Suk Lee, Binod Parameswaran(2008) Journal of Scientific and Industrial Research, 67, 8658733.

[3] Pilanee Vaithanomsat, Sinsupha Chuichulcherm, and Waraporn Apiwatanapiwat, (2009) International Journal of Biological and Life Sciences, 1(1), 21-24.

[4] K.Pakhala, M. Konturri, A. Kallioinen, 0. Myllymäki , J. Uusitalo , M. Siika-aho, N. von Weymarn (2007) Production of Bioethanol from
Barley Staw and Reed Canary Grass: A Raw Material Study, 15 th European Biomass Conference and Exhibition, Berlin, Gemany.

[5] Keikhosro Karimi A.B., Giti Emtiazi C, Mohammad J. Taherzadeh (2006) Enzyme And Microbial Technology, 40, 138-144.

[6] Fatma H. Abd El-Zaher and Fadel (2010) New York Science Journal, 3(4), 72-78.

[7] Elba P.S. Bon, Maria Antonieta Ferrara (2007) An FAO Seminar on The Role of Agricultural Biotechnologies for Production of Bioenergy in Developing Countries, Rome.

[8] Qian Xiang, Lee Y.Y., Pär O. Pettersson, Robert W. Torget (2003) Applied Biochemistry and Biotechnology, 10 (13), 505-514.

[9] Nutawan Yoswathana, Phattayawadee Phuriphipat, Pattranit Treyawutthiwat and Mohammad Naghi Eshtiaghi (2010) Energy Research Journal, 1 (1), 26-31.

[10] Zakpaa H.D., Mak-Mensah E.E. and Johnson F.S. (2009) African Journal of Biotechnology, 8 (13), 3018-3022.

[11] Wilson Parawira (2010) Scientific Research and Essays, 5(14), 1796-1808.

[12] Visser J., Adriaans T. (2007) Anaerobic digestion of jatropha curcas press cake, FACT Fuels Foundation. 0656521-R02, 1-21.

[13] Sadasivam and Manickam (2008) Biochemical Methods, Third Edition, Published by New Age International $(P)$ Ltd.

[14] Arthe R,. Rajesh R., Rajesh E.M., Rajendran R., Jeyachandran (2008) EJEAFChe, 7 (6), 29842992.

[15] Caputi A Jr., Ueda M., Brown T. (1968) Am. J. Enol. Vitic. 19, 160-165.

[16] Nassereldeen A. Kabbashi, Md. Zahangir Alam, M. Fahrurrazi Tompang (2007) IIUM Engineering Journal, 8 (2), 25-36.

[17] David Pimentel and Tad W. Patzek (2005) Natural Resources Research, 14(1), 65-76.

[18] Seema J. Patel, Onkarappa R., Shobha K. S. (2007) The Internet Journal of Microbiology, 4(1). 
Mohit S. Mishra, Chandrashekhar B, Tanushree Chatterjee and Kanwal Singh

Table 1- Day wise estimation of glucose in the fermentation broth in triplicates

\begin{tabular}{|c|c|c|c|c|c|c|c|}
\hline Sample collected & \multirow{7}{*}{$\begin{array}{c}\text { Glucose } \\
\text { estimation by } \\
\text { DNS Method }\end{array}$} & \multicolumn{3}{|c|}{ Optical Density } & \multicolumn{3}{|c|}{ Conc ${ }^{n}$ of glucose, $\mathrm{mg} / \mathrm{ml}$} \\
\hline & & 1st Flask & $2^{\text {nd }}$ Flask & $3^{\text {rd flask }}$ & 1st flask & $2^{\text {nd }}$ flask & $3^{\text {rd }}$ flask \\
\hline Day 1 & & 0.75 & 0.73 & 0.76 & 9.75 & 9.49 & 9.88 \\
\hline Day 3 & & 0.72 & 0.72 & 0.69 & 9.36 & 9.36 & 8.97 \\
\hline Day 5 & & 0.67 & 0.66 & 0.69 & 8.71 & 8.58 & 8.97 \\
\hline Day 7 & & 0.55 & 0.54 & 0.55 & 7.15 & 7.02 & 7.15 \\
\hline Day 9 & & 0.45 & 0.45 & 0.43 & 5.85 & 5.85 & 5.59 \\
\hline
\end{tabular}

Table 2- Day wise estimation of ethanol in the fermentation broth in triplicates

\begin{tabular}{|c|c|c|c|c|c|c|c|}
\hline \multirow[t]{2}{*}{ Sample collected on } & \multirow{7}{*}{$\begin{array}{c}\text { Ethanol estimation } \\
\text { by Dichromate } \\
\text { method }\end{array}$} & \multicolumn{3}{|c|}{ Optical Density } & \multicolumn{3}{|c|}{ Conc $^{\mathrm{n}}$ of ethanol, $\mathrm{ml} / \mathrm{ml}$} \\
\hline & & 1st flask & $2^{\text {nd }}$ flask & $3^{\text {rd flask }}$ & 1st flask & $2^{\text {nd }}$ flask & $3^{\text {rd flask }}$ \\
\hline Day 1 & & 0.080 & 0.082 & 0.077 & 0.016 & 0.0164 & 0.154 \\
\hline Day 3 & & 0.165 & 0.164 & 0.165 & 0.033 & 0.0328 & 0.165 \\
\hline Day 5 & & 0.260 & 0.260 & 0.265 & 0.052 & 0.052 & 0.053 \\
\hline Day 7 & & 0.395 & 0.392 & 0.390 & 0.079 & 0.0784 & 0.078 \\
\hline Day 9 & & 0.425 & 0.425 & 0.425 & 0.085 & 0.085 & 0.085 \\
\hline
\end{tabular}

